\title{
EMPREENDEDORISMO NA GESTÃO UNIVERSITÁRIA
}

\author{
Irineu Manoel de SOUZA ${ }^{1}$ \\ Jane Lucia Silva SANTOS ${ }^{2}$ \\ ${ }^{1}$ Doutor em Engenharia e Gestão do Conhecimento, Professor Adjunto do curso de Administração na Universidade \\ Federal de Santa Catarina (UFSC), Florianópolis-SC, Brasil. E-mail: irineu.manoel@ufsc.br \\ ${ }^{2}$ Doutora em Engenharia e Gestão do Conhecimento, Pesquisadora da Faculdade de Administração na Pontifícia \\ Universidade do Rio Grande do Sul (PUCRS), Porto Alegre-RS, Brasil. E-mail: janejlss@ gmail.com
}

\section{Recebido em: 30/10/2013 - Aprovado em: 15/10/2013 - Disponibilizado em: 15/01/2014}

\begin{abstract}
RESUMO: Este trabalho é um estudo sobre o empreendedorismo na gestão universitária, no qual é apresentado um panorama teórico das abordagens e linhas de estudo identificadas na literatura sobre o tema. As ideias discutidas foram compiladas buscando mostrar a importância do empreendedorismo nas Instituições de Ensino Superior - IES. Neste artigo as IES são vistas como organizações complexas e intensivas em conhecimento, as quais enfrentam vários desafios para desempenhar o seu papel na sociedade e se renovar continuamente ao longo da sua existência. Nesse contexto, incorporar o empreendedorismo na gestão universitária pode trazer diversas vantagens às IES, tais como, ambiente de inovação, estrutura mais ágil e flexível. A partir da discussão fundamentada nos estudos nesse campo de pesquisa, este trabalho contribui para mostrar a relevância do empreendedorismo e seus princípios básicos na gestão universitária; e, serve também para gerar a reflexão sobre a relevância de uma universidade empreendedora que necessita de um modelo de gestão diferenciado e inovador.
\end{abstract}

Palavras-chave: Empreendedorismo. Gestão universitária. Universidade empreendedora. Instituições de Ensino Superior. Empreendedorismo universitário.

ABSTRACT: This is a study about entrepreneurship in the university management, in which it is possible to present a theoretical overview of approaches and research lines identified in the literature on the subject. The discussed ideas were compiled with the intention of showing the entrepreneurship importance at the Higher Education Institutions IES. In this article, the IES are considered as intensive and complex organizations of knowledge that face various challenges in order to play their role in the society, and renew themselves continuously throughout their existence. In this context, to integrate the entrepreneurship in the university management may offer several advantages to the IES, such as innovation environment, more agile and flexible structure. From the discussion based on studies in this field of research, this work helps to show the entrepreneurship relevance and its fundamental principles in the university management. Thus, it also serves to generate a reflection on the importance of an entrepreneurial university that requires a differentiated and innovative management model.

Keywords: Entrepreneurship. University management. Entrepreneurial university. Higher education institutions. University entrepreneurship.

\section{Introdução}

As mudanças no campo econômico, político e social, a nova sociedade do conhecimento, onde o conhecimento é o recurso mais importante e gerador de riqueza, o único capaz de manter a adaptabilidade da organização a novos tempos, a atualidade de seus processos e produtos e sua sustentabilidade (FLEURY, 1994; CHOO, 2006) requer um modelo de universidade inovadora baseado em um novo enfoque de gestão: uma gestão pautada em criatividade, agilidade, flexibilidade e inovação. O que alguns estudos denominam de "universidade empreendedora" (CANO; PULIDO, 2007; OECD, 2012; ETZKOWITZ, 2013).

Devido a esse contexto e ao seu caráter interdisciplinar, as Instituições de Ensino 
Superior - IES estão diante do desafio de transformar um modelo clássico linear para um novo desenho organizacional, adotando novo paradigma educacional centrado na sociedade do conhecimento (ETZKOWITZ, 2013). O empreendedorismo surge como processo da ação e cooperação das pessoas para configurar essa nova forma de administrar as universidades (YILDIRIM; AŞKUN, 2012; OECD, 2012), e destaca-se o relevante papel do gestor/empreendedor na gestão universitária.

Nesse contexto não basta que as instituições universitárias sejam eficazes no cumprimento de sua missão, necessitam serem eficientes em tornar seu produto atrativo ao mercado, diversificar seus produtos de modo que realmente o tripé institucional (ensino, pesquisa e extensão) esteja em harmonia com a comunidade a qual está inserida. Para isto carecem de alterações radicais no modo como são administradas.

Conforme a sua abordagem, os trabalhos nessa área têm adotado diferentes linhas de estudo. Alguns autores (p.ex. RÖPKE, 1998; OECD, 2012; ETZKOWITZ, 2013) têm sugerido que o enfoque no empreendedorismo nas instituições universitárias, segue duas principais direções: (i) a universidade empreendedora, e (ii) a universidade formadora de empreendedores. O primeiro enfoque concentra os esforços da própria instituição, no sentido de tornar seu esforço empreendedor: gestão universitária empreendedora. Já o segundo refere-se a um modelo de ensino que visa contribuir para formar uma visão empreendedora em seus acadêmicos. Este trabalho trata do empreendedorismo na gestão das instituições universitárias (primeiro enfoque mencionado), visando entender melhor o papel que as IES tem desempenhado na atual sociedade do conhecimento, e mantendo este objetivo, o estudo busca compreender as características da gestão universitária numa perspectiva empreendedora, ressaltando a relevância do tema, considerando o seu contexto.

\section{A Universidade e o Empreendedorismo na Gestão Universitária}

\subsection{Instituições Universitárias}

As universidades são vistas pelos estudiosos da área de gestão universitária como organizações complexas. De acordo com Baldridge (1982, p.19), as características organizacionais das “instituições acadêmicas são tão diferentes de outras instituições que as teorias tradicionais da administração não se aplicam a elas”. Ainda para Baldridge (1982) e Rodrigues (1983), é possível identificar as seguintes características que, em geral, são peculiares das organizações universitárias: as universidades possuem uma missão muito ampla, ambígua e intangível, o que gera dificuldades em se definir e operacionalizar objetivos; o planejamento nas universidades é uma atividade isolada e esporádica, funcionando motivado por ciclos de orçamento em curto prazo e por objetivos pessoais, desvinculadamente de definição de estratégias e reexame da finalidade ou missão à 
luz das modificações ambientais; seus profissionais trabalham de modo independente com relação aos seus colegas e a sua forma de trabalho, sendo que eles mesmos controlam suas atividades e resistem à racionalização, impedindo que analistas de estruturas racionalizem suas habilidades; algumas universidades crescem sem que seja feita uma análise concreta da relevância em cada estágio de sua evolução; as organizações universitárias não possuem habilidade gerencial para estabelecer mudanças rápidas; as suas linhas de autoridades são pouco claras; os seus dirigentes funcionam como catalisadores: não mandam, mas negociam, não planificam de forma ampla e tratam de resolver problemas utilizando-se de soluções preexistentes; as mudanças dependem do consenso e da autoridade de uma grande quantidade de pessoas.

As universidades são também enquadradas na literatura, como organizações intensivas em conhecimento - OIC. Destaca-se na literatura acadêmica que tal denominação refere-se àquelas organizações que utilizam fortemente ativos intangíveis, tal como o conhecimento, para a produção de produtos ou serviços (FLEURY, 1994; STEWART, 1998). Desta forma, quanto maior o papel do conhecimento na criação de valor para os produtos ou serviços de uma organização, maior será a importância da atividade intelectual de colaboradores altamente qualificados. Assim, as pessoas que integram as OIC devem ser orientadas para o conhecimento.
Sinteticamente, a organização intensiva em conhecimento é uma organização que tem o conhecimento como principal recurso estratégico e o trabalhador do conhecimento é o componente crítico (GARVIN, 1993).

As OIC podem ser caracterizadas como organizações que têm a gestão do conhecimento como uma política que orienta as suas estratégias globais, estruturam-se em torno de resultados e não de tarefas, gerenciam as suas bases de conhecimento, melhorando a eficácia, as suas capacidades de inovar, a qualidade e a equidade de seus produtos e/ou serviços; têm a capacidade de gerenciar, de forma simultânea, as mudanças tecnológicas e sociais; são organizações que "empoderam" as pessoas que nelas atuam; e nas quais as decisões sobre o trabalho são tomadas por aqueles que o executam (CHOO, 2006).

Nos projetos dentro das OIC, os atores principais são: os indivíduos que tem conhecimentos, habilidades, experiências e capacidades de aprendizagem que são evidenciadas em termos de comportamento e de atitudes; e o grupo (equipe de projeto) que utiliza a sua sinergia a fim de alcançar os objetivos desejados. As pessoas (competências, e relacionamentos), tecnologias (técnicas e interações homem-máquina) e processos (procedimentos, sistemas) são elementos dos ativos intangíveis que juntos vão formar o Conhecimento Organizacional (DAVENPORT; PRUSAK, 1999). Os ativos intangíveis, também chamados de capital intelectual, estão 
disseminados por toda a organização e a sua manutenção é dinâmica. Pode-se deduzir que as organizações que buscam evoluir, principalmente na inovação esse fator é crítico (EDVINSSON; MALONE, 1998; STEWART, 1998). A inovação é a maneira como a organização deve agir para ter sucesso na dimensão organizacional, na dimensão humana e na dimensão externa. A inovação pode ser vista como a energia de uma organização, a qual afeta o seu contexto interno e o seu entorno, ou seja, os relacionamentos internos e externos que movem a organização (GERBER, 2004).

Semelhante às OIC, as instituições universitárias trabalham com múltiplas fontes de conhecimento: pessoas, cultura organizacional, sistemas administrativos, sistemas computacionais, rotinas e procedimentos, gerenciam as suas bases de conhecimento, melhorando a eficácia e as capacidades de inovação. De acordo com Pinchot e Pellman (1999), para que a inovação aconteça é necessário: ideias das pessoas deve-se ter na organização um ambiente que estimule a criatividade e a geração de ideias; intraempreendedores: são as pessoas que transformam as ideias em realidade; equipe intraempreendedora: consiste em um grupo de pessoas, normalmente recrutadas pelo intraempreendedor, para trabalharem na inovação; clima organizacional: deve existir um clima organizacional que estimule e aceite inovações; patrocinadores: são pessoas da própria organização que apoiam os intraempreendedores - pode ser um chefe imediato ou o presidente da empresa.

Assim, o principal desafio é criar um ambiente propício para o surgimento dos intraempreendedores. As organizações precisam criar ambientes adequados para que os intraempreendedores sejam descobertos e incentivados. Gerber (2004, p. 82-83) afirma que o processo de desenvolvimento da empresa é dinâmico apenas porque o mundo, movendo como se move, não tolerará um objeto estacionário; o mundo se chocará com o que quer que você tenha criado e, mais cedo ou mais tarde, o destruirá. De acordo com o citado autor, o processo de desenvolvimento das empresas é o que permite o ajuste às mudanças do mundo e as pode preceder, ou antecipar, ou ao menos ser infinitamente flexível na relação com estas empresas.

Nesse contexto, o empreendedorismo na gestão universitária é fundamental, contudo deve haver o entendimento de que o conhecimento está nos indivíduos (NONAKA; TACHEUCHI, 1997) e com eles permanecerá enquanto fizerem parte da organização. Assim, o caráter intangível do conhecimento caracteriza a complexidade das instituições universitárias.

A partir desta perspectiva conceitual, entendese que o empreendedorismo pode contribuir para uma melhor compreensão das características e a gestão dessas organizações do conhecimento. 


\subsection{Empreendedorismo na Gestão Universitária}

Os estudos sobre empreendedorismo nas instituições universitárias têm assumido, pelo menos, dois enfoques (que podem ser complementares): o de universidade empreendedora e o de universidade formadora de empreendedores (RÖPKE, 1998; OECD, 2012; ETZKOWITZ, 2013). O primeiro enfoque, lente adotada neste trabalho, se concentra nos esforços da própria instituição, no sentido de tornar seu esforço empreendedor: gestão universitária empreendedora. Já o segundo refere-se a um modelo de ensino que busca desenvolver e formar uma visão empreendedora em seus acadêmicos. O cenário que marca os últimos anos, praticamente obrigou as universidades dispostas, a prosperarem e cumprirem com maior amplitude sua missão, a tornarem-se empreendedoras, criativas, a gerirem suas funções mais efetivamente, priorizando um novo desenho organizacional que lhe confere a agilidade e a flexibilidade necessária ao alto desempenho organizacional desejado: a nova "universidade empreendedora" diz respeito à análise introspectiva do seu saber fazer (RODRIGUES; TONTINI, 1997).

$\mathrm{Na}$ literatura sobre o tema há várias definições e descrições do que se entende por universidade empreendedora, ao longo dos anos (Quadro 1).

Quadro 1 - Definições e descrições sobre universidade empreendedora

\begin{tabular}{|c|c|}
\hline Autor (ano) & Definições \\
\hline Etzkowitz (1983) & $\begin{array}{l}\text { São universidades que estão considerando novas fontes de recursos, tais como, patentes } \\
\text { e pesquisa por contratos, e a entrada em parcerias com empresa privada. }\end{array}$ \\
\hline $\begin{array}{l}\text { Chrisman, Hynes e } \\
\text { Fraser (1995) }\end{array}$ & $\begin{array}{l}\text { Envolve a criação de novos empreendimentos por professores universitários, técnicos ou } \\
\text { alunos. }\end{array}$ \\
\hline Clark (1998) & $\begin{array}{l}\text { Uma Universidade Empreendedora, por si só, procura inovar na maneira como conduz } \\
\text { os seus negócios. Pretende-se trabalhar uma mudança substancial no caráter } \\
\text { organizacional, de modo a chegar a uma postura mais promissora para o futuro. } \\
\text { Universidades empreendedoras procuram tornar-se universidades stand-up. }\end{array}$ \\
\hline Röpke (1998) & $\begin{array}{l}\text { A Universidade Empreendedora pode significar três coisas: a própria universidade, como } \\
\text { organização, torna-se empreendedora; os membros da universidade - professores, alunos, } \\
\text { funcionários, se transformando de alguma forma em Empreendedores, e; da interação da } \\
\text { universidade com o seu entorno, o "acoplamento estrutural" entre a universidade e a } \\
\text { região. }\end{array}$ \\
\hline Subotzky (1999) & $\begin{array}{l}\text { A Universidade Empreendedora é caracterizada pelo estreitamento de parcerias } \\
\text { universidade-empresa, por uma maior responsabilidade de acesso a fontes externas de } \\
\text { financiamento, e por um "ethos" empresarial na governança, liderança e planejamento } \\
\text { institucional. }\end{array}$ \\
\hline Kirby (2002) & $\begin{array}{l}\text { Universidades empreendedoras têm a capacidade de inovar, reconhecer e criar } \\
\text { oportunidades, trabalhar em equipe, assumir riscos e responder aos desafios. }\end{array}$ \\
\hline Etzkowitz (2003) & $\begin{array}{l}\text { Assim como a universidade treina os alunos individuais e envia-os para o mundo, a } \\
\text { Universidade Empreendedora é uma incubadora natural, proporcionando estruturas de } \\
\text { apoio para professores e alunos para iniciar novos empreendimentos: intelectual, } \\
\text { comercial e conjuntos. }\end{array}$ \\
\hline $\begin{array}{l}\text { Jacob, Lundqvist e } \\
\text { Hellsmark (2003) }\end{array}$ & $\begin{array}{l}\text { Uma Universidade Empreendedora é baseada tanto na comercialização (de cursos de } \\
\text { ensino superior, serviços de consultoria e atividades de extensão) como na }\end{array}$ \\
\hline
\end{tabular}




\begin{tabular}{|l|l|}
\hline & "comoditização" (patentes, licenciamento ou star-ups de propriedade de estudantes). \\
\hline Cano e Pulido (2007) & $\begin{array}{l}\text { É uma universidade que tem a capacidade de inovar, reconhecer e criar oportunidades, } \\
\text { trabalhar em equipe, assumir riscos e responder aos desafios, e que procura trabalhar } \\
\text { uma mudança substancial no caráter organizacional para se chegar a um futuro } \\
\text { promissor. }\end{array}$ \\
\hline OECD (2012) & $\begin{array}{l}\text { É uma organização que faz inovação ao longo de suas pesquisas, o intercâmbio de } \\
\text { conhecimento, ensino e aprendizagem, governança e relações externas. }\end{array}$ \\
\hline Etzkowitz (2013) & $\begin{array}{l}\text { É uma instituição que faz da transferência de tecnologia, criação de empresas e } \\
\text { desenvolvimento regional uma missão acadêmica, integrando-os em educação e pesquisa } \\
\text { da universidade. }\end{array}$ \\
\hline
\end{tabular}

Fonte: Elaboração própria (Adaptado de CANO; PULIDO, 2007, com atualização até 2013).

Ao observar essas definições é possível identificar algumas das características das universidades empreendedoras, ao mesmo tempo em que apontam uma lacuna que reflete a falta de definição e uma descrição comum, o que pode impactar no desenvolvimento de estudos neste campo.

As características da universidade empreendedora podem ser compreendidas como um conjunto de quatro princípios interrelacionados (Quadro 2), que recentemente foram sintetizados no trabalho de Etzkowitz (2013): interação, independência, hibridização e reciprocidade.

Quadro 2. Características da universidade empreendedora

\begin{tabular}{|l|l|}
\hline $\begin{array}{l}\text { Características } \\
\text { inter-relacionadas }\end{array}$ & Descrição \\
\hline $\begin{array}{l}\text { Interação } \\
\text { A universidade empreendedora } \\
\text { interage estreitamente com a } \\
\text { indústria e o governo, não é uma } \\
\text { universidade "torre de marfim" } \\
\text { isolada da sociedade. }\end{array}$ \\
\hline $\begin{array}{l}\text { Independência } \\
\text { uma iniversidade empreendedora é } \\
\text { independente, não é uma criatura } \\
\text { dependente de outra esfera } \\
\text { institucional. }\end{array}$ \\
\hline 3. & $\begin{array}{l}\text { A resolução das tensões entre os } \\
\text { princípios de interação e } \\
\text { independência são um impulso para } \\
\text { a criação de formatos } \\
\text { organizacionais híbridos para } \\
\text { realizar ambos os objetivos ao } \\
\text { mesmo tempo. }\end{array}$ \\
\hline 4. & Há uma renovação contínua da \\
\hline
\end{tabular}

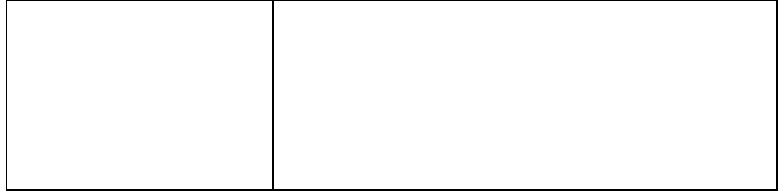

Fonte: Elaboração própria (baseado em ETZKOWITZ, 2013, p. 491-492).

Os princípios 1 e 2 podem ser entendidos, também, como princípios institucionais de pesquisa e ensino da universidade, e é a confluência de todos os quatro elementos que contribui para uma plena universidade empreendedora (ETZKOWITZ, 2013).

Alguns autores (p. ex., LEITE, 2000; CANO; PULIDO, 2007; ETZKOWITZ, 2013) têm apontado que no campo de pesquisa sobre empreendedorismo existe uma crença de que o papel de empreender é executado por um indivíduo (um empreendedor) que assume grandes riscos para iniciar uma nova atividade, e que as organizações têm a função de institucionalizar e perpetuar um negócio nascido da ideia do empreendedor. Ou seja, o conceito tradicional de empreendedorismo pressupõe que o empreendedor é uma pessoa individual, em vez de uma organização como uma universidade. Todavia, existem vários casos de universidades empreendedoras, 
inclusive no Brasil.

Um exemplo desse esforço é exposto pela Universidade Estadual de São Paulo - UNESP.

A UNESP destaca-se como a segunda maior universidade pública do país - a despeito do seu pouco tempo de existência. Segundo depoimento do seu ex-reitor, José Carlos Souza Trindade, o espírito inovador e empreendedor dessa entidade levaram-na ao lugar de destaque que hoje ostenta. Nos últimos anos, ações como: a criação de novos campi e novos cursos; a ampliação de vagas no Vestibular; a criação de mais de 1.000 cargos estatutários; a implantação de programas em parceria com o poder público municipal; a ampliação do corpo docente e dos servidores técnicoadministrativos; os investimentos em informática; os programas de Pós-Graduação e Pesquisa, dentre outras, derivaram no expressivo crescimento da sua estrutura, com quase 30 mil alunos de graduação, mais de sete mil em pós-graduação, atendidos por mais de 3.000 docentes e 6.000 servidores técnicoadministrativos. $\mathrm{O}$ Professor Jacques Marcovitch, ex-reitor da Universidade de São Paulo - USP, de maneira similar listou os avanços conquistados pela USP nos últimos anos: aumento mais de mil novas vagas no vestibular; criação de 19 cursos novos, conquista dos CEPIDs (Centros de Pesquisa, Inovação e Difusão); avanço em tecnologia da informação com o portal da USP, a "cidade do conhecimento" e a biblioteca digital; todos como sendo ferramentas que aproximam a universidade da sociedade que a mantém. O reitor da USP, ao ser questionado sobre qual seria o principal problema dessa entidade, manifestou-se assim: "A USP é muito complexa. Eu diria que o desafio maior é o de como fazer com que, respeitando os tempos e os valores das várias áreas do conhecimento, seja possível viver numa instituição que precisa ser cada vez mais empreendedora e generosa porque precisa atender vários segmentos da sociedade - e ainda preservar a sua essência de formação de lideranças". O problema pautado pelo reitor da USP não parece ser estranho às demais entidades congêneres, sejam elas públicas ou privadas (CAFARDO, 2004).

Importante levar em consideração que o papel das instituições de ensino superior denota, com clareza, a necessidade de se adotar um novo paradigma educacional que deverá estar centrado na sociedade do conhecimento, consequentemente cada vez mais baseado em informações e no conhecimento.

De acordo com Leite (2000, p. 533), “o modelo organizacional em que assenta hoje o ensino superior está, ao que parece, esgotado. É preciso (re) institucionalizar e (re) inventar o ensino superior brasileiro, baseado no empreendedorismo". Dentro dessa linha de raciocínio, a função de uma instituição de ensino superior torna-se muito mais importante, pois é ela a verdadeira responsável pela produção e disseminação do conhecimento. Nas atuais condições, a própria instituição de ensino superior tem de assumir, cada vez mais, 
o perfil de uma organização de aprendizagem.

Essa preocupação é recente no universo das instituições de ensino superior brasileiras.

Não é demais destacar que nas organizações intensivas em conhecimento, as pessoas não são treinadas para exercerem suas funções, mas sim educadas a desempenharem com satisfação suas atividades, desenvolvendo o espírito de equipe e criatividade, sendo respeitadas em sua individualidade e autonomia desenvolvendo, assim, um trabalho com excelência. $\mathrm{O}$ ambiente favorece a criação de objetivos compartilhados, gerando um sentimento de coletividade que permeia a organização e dá coerência às diferentes atividades, contribuindo para o engajamento e a participação das pessoas na resolução de problemas institucionais do ensino superior brasileiro.

Segundo Fleury (1994, p. 232), “ o conceito de organizações intensivas em conhecimento implica: na superação do modelo taylorista de separação entre os que pensam e os que executam; envolve um processo contínuo de inovação e aprendizagem coletiva a ser realizado por todos os membros da organização; em uma organização inovativa, qualificante, onde os objetivos organizacionais são explicitados e compartilhados, pois há um comprometimento com o projeto de desenvolvimento organizacional, que é consistente com o projeto de desenvolvimento individual; e no processo de formação de gestores para as organizações, promovendo o desenvolvimento de habilidades de autoconhecimento da cultura organizacional.

Os empreendedores são fundamentais para o sucesso de uma organização também porque antecipam o problema e o resolvem; eles assumem responsabilidades e possuem um significado determinante diante do alcance dos objetivos organizacionais. Há uma variada gama de habilidades que oferece ao empreendedor a possibilidade de obtenção de sucesso junto a sua organização. As diversas teorias que orientam os programas mais avançados de formação de empreendedores no mundo moderno apregoam que o fundamental é preparar as pessoas para aprenderem a agir e a pensar, com criatividade e utilizando a liderança e visão de futuro para inovarem. Também a partir das experiências internacionais bem-sucedidas, já se sabe que as principais organizações para a realização dessa mudança cultural são as próprias instituições de ensino superior. A instituição de ensino superior, nesse processo, é considerada o ponto de partida, porque ela é, por excelência, uma fonte multiplicadora do saber e forte formadora de opinião.

\section{Considerações Finais}

Com base na fundamentação teórica trabalhada nesta pesquisa bibliográfica, considerou-se que que as universidades são instituições diferenciadas, e percebe-se que o empreendedorismo pode contribuir para desenvolver um novo modelo de gestão universitária, a fim de atingir a excelência na 
gestão dessas instituições. Entende-se assim que o empreendedorismo busca conceber a organização como um espaço dinâmico e constituído de inovação e aprendizagem, e que permite agregar o conhecimento no modelo estratégico de se administrar as IES. Com efeito, a tendência da gestão universitária (principalmente na Europa) evidencia que o que realmente importa são as soluções que há para os novos problemas, para a universidade sobreviver nesta era da globalização e da sociedade do conhecimento e economia empreendedora. Pode-se perceber por esse estudo que diante desta realidade, os gestores universitários precisam analisar como a importância crescente do empreendedorismo pode interferir na busca de novos modelos eficazes de gestão das universidades.

Utilizando-se de conceitos propostos por autores como Nadler, Gerstein e Shaw (1994), além das características das organizações da Sociedade do Conhecimento referenciadas por Garvin (1993), pode-se discutir novos modelos de gestão para as universidades, tendo como fundamento principalmente: a sua estrutura, processos, tecnologia e pessoas. A complexidade das instituições universitárias exige uma gestão diferenciada das demais organizações tradicionais, e novos modelos dinâmicos de gestão para lidar com essa complexidade. Gerir uma instituição universitária não implica atender apenas a um determinado grupo de interesse. Ao contrário, uma universidade é povoada por diversos centros de poder que de algum modo precisam ser conciliados. Assim, infere-se que a gestão universitária poderá orientar-se pelas abordagens propostas pelo empreendedorismo. Este trabalho apresentou um embasamento teórico que pode ser útil para realização de futuras pesquisas nessa área. Sabe-se que uma instituição de ensino superior tem a sua missão voltada para a comunidade em que está inserida, sendo que deve ser ela a precursora do novo, o espaço das diferenças, da tolerância, da interdisciplinaridade e da dialética, e por isso a referência para as soluções inovadoras dos mais variados problemas sociais. Um agente ativo e transformador da sociedade e da educação.

Em suma, incorporar o empreendedorismo na gestão universitária pode trazer diversas vantagens às IES, tais como, ambiente de inovação, estrutura mais ágil e flexível. A partir da discussão fundamentada nos estudos nesse campo de pesquisa, este trabalho contribui para mostrar a relevância do empreendedorismo e seus princípios básicos na gestão universitária; e, serve também para gerar a reflexão sobre a relevância de uma universidade empreendedora norteada por um modelo de gestão diferenciado e inovador.

\section{REFERÊNCIAS}

BALDRIDGE, J. Vistor et al. Estructuracion de Políticas y Liderozgo Efectivoen da Educacion. México, H.O.E.M.A., 1982. CAFARDO, Renata. USP Precisa ser mais Empreendedora, diz Reitor. O Estado de S. 
Paulo, São Paulo, 15 out 2004. Disponível em <http://www.estado.estadao.com.br/editorias/ge r011.html >. Acesso em: 3 set. 2013.

CANO, Maribel Guerrero; PULIDO, David Urbano. Entrepreneurial Universities: The Case of Autonomous University of Barcelona. 2007.

CHOO, C.W. The Knowing organization: How organizations use information to construct meaning, create knowledge, and make decisions. Second Edition, Oxford University Press, New York, 2006.

DAVENPORT, Thomas; PRUZAK, Laurence. Conhecimento Empresarial. Campus, 1999.

EDVINSSON, Leif; MALONE, Michael S. Capital Intelectual: descobrindo o valor real de sua empresa pela identificação de seus valores internos. São Paulo: Makron Books, 1998.

ETZKOWITZ, Henry. Anatomy of the entrepreneurial university. Social Science Information, v. 52, n. 3, p. 486-511, 2013.

FLEURY, Maria Tereza Leme. Inovação e Gestão: o perfil do gestor de uma 'learning organization'. Revista Brasileira de

Administração Contemporânea. p. 223-233, 1994.

GARVIN, D. Building a Learning Organization. Harvard Business Review.

Boston, p. 78-91, jul./ago, 1993.

GERBER, Michael E. Empreender fazendo a diferença. São Paulo: Fundamento, 2004.

LEITE, Emanuel. $\mathbf{O}$ fenômeno do

empreendedorismo: criando riquezas. Recife: Bagaço, 2000.

NADLER, D.; GERSTEIN, M. S.; SHAW, R. B. Arquitetura organizacional: a chave para a mudança empresarial. 2. ed. Rio de Janeiro: Campus, 1994.
NONAKA, I.;TACHEUCHI, H. Criação do Conhecimento na Empresa. $1^{\text {a }}$ ed., São Paulo: Editora Campus, 1997.

OECD. European Commission - Organisation for Economic Co-operation and Development. A Guiding Framework for Entrepreneurial Universities, 2012. Disponível em: http://www.oecd.org/site/cfecpr/ECOECD\%20Entrepreneurial\%20Universities\%2 OFramework.pdf. Acesso: 28/10/2013.

PINCHOT, Gifford. Intrapreneuring. São Paulo, Habra, 1989.

PINCHOT, Gifford. PELLMAN, Ron. Intrapreneuring in action - a handbook for business innovation. San Francisco: BerrettKoehler Publishers, Inc, 1999.

RODRIGUES, Leonel Cezar; TONTINI, Gérson. A universidade empreendedora: geração e transferência de tecnologia como fator agregador. Revista de Negócios da FURB, Blumenau, n. 2, p. 37-49, 1997.

RÖPKE, J. The Entrepreneurial University, Innovation, academic knowledge creation and regional development in a globalized economy. Working Paper. Department of Economics, Philipps- Universität Marburg, Germany: 15, 1998.

STEWART, Thomas A. Capital intelectual: a nova vantagem competitiva das empresas. Rio de Janeiro: Ed. Campus, 1998.

TRINDADE, José Carlos Souza. Jubileu de Prata da UNESP. Jornal da UNESP, São Paulo, Mar. 2002. Disponível em < http://www.unesp.br/jornal/encartejubileu.htm >. Acesso em: 3 set. 2008.

YILDIRIM, Nihan; AŞKUN, Olcay Bige. Entrepreneurship Intentions of Public Universities in Turkey: Going Beyond Education and Research? Procedia-Social and Behavioral Sciences, v. 58, p. 953-963, 2012. 